\title{
Speech compensation to structural modifications of the oral cavity
}

David H. McFarland, Shari R. Baum, and Caroline Chabot

Citation: The Journal of the Acoustical Society of America 100, 1093 (1996); doi: 10.1121/1.416286

View online: https://doi.org/10.1121/1.416286

View Table of Contents: https://asa.scitation.org/toc/jas/100/2

Published by the Acoustical Society of America

\section{ARTICLES YOU MAY BE INTERESTED IN}

Incomplete compensation to articulatory perturbation

The Journal of the Acoustical Society of America 97, 1865 (1995); https://doi.org/10.1121/1.412060

Production of bite-block vowels: Acoustic equivalence by selective compensation

The Journal of the Acoustical Society of America 69, 802 (1981); https://doi.org/10.1121/1.385591

The development of speech adaptation to an artificial palate

The Journal of the Acoustical Society of America 102, 2353 (1997); https://doi.org/10.1121/1.419619

Compensation strategies for the perturbation of the rounded vowel [u] using a lip tube: A study of the control space in speech production

The Journal of the Acoustical Society of America 98, 2428 (1995); https://doi.org/10.1121/1.413277

Learning to produce speech with an altered vocal tract: The role of auditory feedback

The Journal of the Acoustical Society of America 113, 532 (2003); https://doi.org/10.1121/1.1529670

Acoustical Consequences of Lip, Tongue, Jaw, and Larynx Movement

The Journal of the Acoustical Society of America 50, 1166 (1971); https://doi.org/10.1121/1.1912750

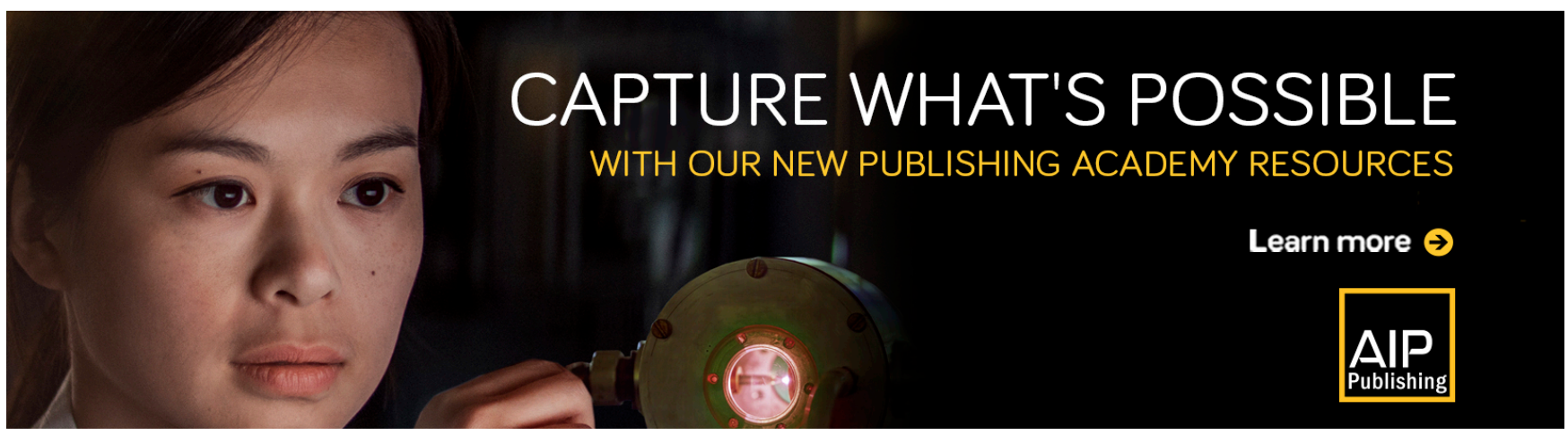




\title{
Speech compensation to structural modifications of the oral cavity
}

\author{
David H. McFarland ${ }^{\text {a) }}$ \\ École d'orthophonie et d'audiologie, Université de Montréal, C.P. 6128, Succursale Centre-Ville, Montréal, \\ Québec H3C 3J7, Canada \\ Shari R. Baum \\ School of Communication Sciences and Disorders, McGill University, 1266 Pine Avenue W., Montréal, \\ Québec H3G 1A8, Canada \\ Caroline Chabot \\ École d'orthophonie et d'audiologie, Université de Montréal, C.P. 6128, Succursale Centre-Ville, Montréal, \\ Québec H3C 3J7, Canada
}

(Received 20 August 1995; accepted for publication 25 February 1996)

\begin{abstract}
Acoustic and perceptual analyses of vowels, stops, and fricatives produced with and without an artificial palate were conducted. Recordings were made both immediately upon insertion of the palate and following a 15-min adaptation period. Results of the acoustic analyses revealed significant alterations in the fricative spectra under conditions of perturbation with fewer, if any, changes in the vowels and stop consonants. Perceptual data confirmed these patterns and provided evidence of possible improvements in compensation over time. The data are compared to our previous studies of speech sound articulation under bite-block conditions. Differences between adaptation to modifications of oral structure (artificial palate) and oral function (jaw fixation by a bite block) are considered. (c) 1996 Acoustical Society of America.
\end{abstract}

PACS numbers: 43.70.Aj, 43.70.Fq [AL]

\section{INTRODUCTION}

Observing speech compensation to oral-articulatory perturbations has provided valuable insights into many important issues in speech motor control. Among them is the extent to which somatosensory and/or auditory feedback interact with central control signals in the production of speech (Kent et al., 1990; McFarland and Lund, 1995; Smith, 1992). Adaptation to perturbations reveals our capacity to use sensory feedback and to form articulatory programs that are appropriate for the changed environment. Perturbations or alterations to the oral-articulatory system that have been studied may be generally classified into functional and structural modifications.

Functional perturbations interfere with the movements or positioning of speech articulators without modifying their structure. Dynamic functional perturbations have been used to rapidly impede ongoing speech articulation. Many studies have explored speech production with the mandible or lower lip unexpectedly lowered by the application of a load (e.g., Abbs and Gracco, 1984; Gracco and Abbs, 1988; Folkins and Zimmerman, 1982; Kelso et al., 1984; Munhall et al., 1994). In general, results have revealed the immediacy of speech compensation and the potential contribution of sensory information in the adaptive process. The specific pathways involved, however, are unclear, and disagreements exist over the contribution of brain-stem reflex versus transcortical feedback processes in the modification of speech gestures (see Smith, 1992). Recent data suggest that

\footnotetext{
a) Author to whom correspondence should be addressed. E-mail: mcfarlad@ere.umontreal.ca
}

the degree of adaptation to dynamic articulatory perturbation is subject-dependent and indicative of individual compensatory strategies (Munhall et al., 1994).

For purposes of the present investigation, we will focus on static functional perturbations of the oral environment such as the fixation of the jaw by means of a bite block. Despite previous claims that there is both immediate and complete compensation to this articulatory perturbation, more recent work (Flege et al., 1988; Fowler and Turvey, 1980), including our own (Baum et al., 1995; McFarland and Baum, 1995), suggests that there are small but significant differences in acoustic, physiological, and perceptual characteristics of vowels and consonants produced under bite-block and normal conditions. Furthermore, there is some improvement in the accuracy of vowel production during a period of adaptation with the bite block in place, suggesting that speech compensatory strategies develop over time using error-based correction. Consonants, and in particular fricatives, appear particularly resistant to adaptation perhaps because they require greater articulatory precision than other sound classes such as vowels (McFarland and Baum, 1995; Stoel-Gammon and Dunn, 1985).

Structural perturbations can be either clinically or experimentally introduced changes to the vocal tract that do not directly impede movement. There are a variety of clinical conditions that may introduce structural changes to the oral environment and, in turn, affect speech. Missing or misaligned teeth, malocclusions, dental prostheses, and orthodontic appliances all have the potential to adversely influence speech articulation. Most of this work has focused on the effects of various types of dental prostheses, and clinical 
observations have shown that the presence of such appliances can result in significant speech articulation errors (Chaney et al., 1978; Palmer, 1979; Tanaka, 1973).

Artificial palates placed in the mouths of otherwise normal speakers may result in distortions of both vowel and consonant articulation, but consonants may be selectively impaired. Articulation errors have been found to increase in proportion to the thickness of the alveolar-palatal acrylic (Hamlet, 1973; Hamlet and Stone, 1974; Hamlet and Stone, 1978; Hamlet et al., 1979). The presence of artificial palates also increases the duration of the consonants $[\mathrm{s}]$ and $[\mathrm{z}]$, as the tongue contacts the alveolar ridge earlier and releases later than under control conditions (Hamlet et al., 1979; Hamlet and Stone, 1978). Artificial palates appear to require a lengthy adaptation period, perhaps involving days or weeks, before normal speech is approached. However, more rapid changes in speech articulation, presumably reflecting compensatory strategies, have been observed 15 min after the insertion of appliances (Hamlet and Stone, 1974).

Although each has been relatively intensely studied, the perturbing effects of bite blocks and artificial palates have not been directly compared. There may be a number of critical differences between these two types of perturbations. First, it seems likely that speech sounds of different phoneme classes may be differentially affected by bite blocks versus artificial palates. Covering the palatal surface may be particularly detrimental to sibilants, for which a precise positioning of the tongue relative to the palatal surface is required. A fixed jaw opening associated with the presence of a bite block, on the other hand, may be more detrimental to vowel production because of the important contribution of jaw opening to vowel formant structure (Lindblom and Sundberg, 1971).

It also seems likely that the time course of compensation will differ between bite block and palatal alterations. Speech has been found to gradually and progressively improve following insertion of an artificial palate (Hamlet and Stone, 1976a, b; Hamlet et al., 1978; Hamlet and Stone, 1978) or a dental prosthesis (Allen, 1958; Chierici and Lawson, 1973; Palmer, 1979; Tanaka, 1973). These data have been interpreted to suggest that a new set of articulatory programs are developed for the change in oral structure. These programs take time to develop, but once established they can be recalled quickly (Hamlet et al., 1978). In contrast, the majority of the evidence suggests that compensation to bite blocks will not require as lengthy an adjustment period as adaptation to palatal appliances, at least for certain sound classes (Gay et al., 1981; Kelso and Tuller, 1983; Lindblom et al., 1979).

The present investigation was designed to examine in detail the adaptation to artificial palates of two thicknesses placed in the mouths of otherwise normal speakers. The methods employed followed as closely as possible those used in our earlier bite-block studies (Baum et al., 1996; McFarland and Baum, 1995) with the eventual goal of comparing these two forms of oral-articulatory perturbations. Acoustic and perceptual variables were studied over time to provide a multilevel analysis of the nature and time course of the compensatory process.

\section{METHODS}

\section{A. Acoustic analyses}

\section{Subjects}

The subjects included fifteen adult female native speakers of (Quebec) French (aged 20-23) with no history of speech and/or language disorders. All speakers passed an audiometric screening ( $<15 \mathrm{~dB} \mathrm{HL}$ at $0.5,1.0$, and $2.0 \mathrm{kHz})$, and were screened to assure normal occlusal relationships (normal bite) and palatal configurations.

\section{Artificial palates}

A dentist assisted in the fabrication and insertion of two alveolar-palatal acrylic appliances for each subject. The prostheses were similar to orthodontic retainers except for the fact that the alveolar-palatal contour was lowered and retracted in order to perturb oral cavity structure. The two appliances differed only in alveolar-palatal thickness, the first prosthesis being $6 \mathrm{~mm}$ thick at the midline of the cuspid-tocuspid plane from the incisive papilla to $2 \mathrm{~mm}$ posterior to the cuspids. Posterior to the plane the appliance tapered to a thickness of approximately $2 \mathrm{~mm}$. An alveolar thickness of 6 $\mathrm{mm}$ was the largest that could be used without interfering with normal occlusion. Ball clasps were used to hold the prostheses securely but comfortably in the subject's mouth. The second prosthesis was identical to the first except that it had an alveolar thickness of 3 as opposed to $6 \mathrm{~mm}$.

\section{Stimuli}

Stimuli included the three vowels $[\mathrm{i}$ a $\mathrm{u}]$ produced in isolation, the voiceless stop consonants [p t $\mathrm{k}$ ] in the environment preceding the same three vowels, and the voiceless fricatives [s $\left.\int\right]$ in the same vowel environments. Each stimulus was presented in orthographic form on a computer screen placed 25 in. from the subjects at eye level. Five repetitions of each stimulus were elicited in random order in each of a series of perturbed and unperturbed conditions as described below.

\section{Procedure}

As in our previous bite-block study (McFarland and Baum, 1995), two subtests, immediate and postconversation, were run over three different experimental sessions on separate days. Three conditions were included in the immediate compensation subtest: no artificial palate (no palate), thin (3 $\mathrm{mm})$ artificial palate, and thick $(6 \mathrm{~mm})$ artificial palate. For the postconversation subtest, the thick palate was compared to the no palate condition. The stimuli in the postconversation condition were elicited following a 15-min period of conversation with the thick palate in place to determine whether speakers would accommodate to the perturbation subsequent to a short period of practice. Presentation of the blocks of vowel and consonant-vowel stimuli were counterbalanced within each subtest. Subjects inserted and removed the artificial palates for each trial (regardless of whether the subsequent trial required the same palate). A digital audio tape recorder (Sony DTC-57ES) and a directional micro- 
TABLE I. Acceptable frequency ranges $(\mathrm{Hz})$ for $F 1$ and $F 2$.

\begin{tabular}{ccr}
\hline \hline & $F 1$ & \multicolumn{1}{c}{$F 2$} \\
\hline$[\mathrm{u}]$ & $200-500$ & $700-1600$ \\
{$[\mathrm{a}]$} & $600-900$ & $900-1600$ \\
{$[\mathrm{i}]$} & $200-500$ & $1700-2700$ \\
\hline \hline
\end{tabular}

phone (Sennheiser MD421U) placed approximately ten inches in front of the speaker's mouth were used to record speaker's productions.

\section{Analyses}

Vowel and stop-vowel stimuli were digitized at a rate of $10 \mathrm{k}$ samples/s with a $4.5-\mathrm{kHz}$ low-pass filter and 12-bit quantization using the BLISS speech analysis system. The fricative-vowel stimuli were digitized at $20 \mathrm{k}$ samples/s with $9-\mathrm{kHz}$ low-pass filtering. Both temporal and spectral measures were computed for each stimulus. First, for each token, the duration of the target vowel or consonant was determined from the waveform display. Vowel durations were measured from the onset of voicing through the end of periodicity. Stop consonant durations (defined here as voice onset time) were delineated by the burst associated with the stop release and the end of aspiration noise and the onset of periodicity associated with the following vowel. For fricatives, the time from the onset of frication noise to the end of the noise segment and onset of vocalic periodicity was measured.

Next, for vowel segments, the first two formant frequencies were identified at two points in the waveform to examine the immediacy of compensation. The formants were extracted via linear-predictive coding (LPC) analysis using a 14-pole network, and a $25.6 \mathrm{~ms}$ full Hamming window was placed at the first glottal pulse of the vowel. A range of acceptable formant values was used to avoid errors in the extraction algorithm; if the $F 1$ or $F 2$ values did not fall within that range (see Table I and Delattre, 1966; McFarland and Baum, 1995; Peterson and Barney, 1952), the number of poles in the LPC algorithm was adjusted and the formants were recomputed. Values that remained out of range were excluded from the analyses (Baum and Katz, 1988; McFarland and Baum, 1995). F1 and $F 2$ values were computed in the same fashion at the midpoint of the vowel. If the adjustment of LPC poles did not yield appropriate values, the window was shifted $\pm 20 \mathrm{~ms}$ and the analysis recomputed. As above, frequency values outside the range limits were excluded (a total of $5 \%$ and $4 \%$ of the $F 1$ and $F 2$ values, respectively, across both window positions were eliminated via this procedure).

For stop and fricative consonants, the spectral analyses included measures of the first (centroid), third (skewness), and fourth (kurtosis) moments of the consonantal spectral distributions (following Forrest et al., 1988). The centroid represents a weighted average of the spectral peak frequencies, and was used previously by us (McFarland and Baum, 1995) to summarize consonant spectral energy concentration and to assess the acoustic consequences of speech compensation (or lack thereof) to increased jaw opening. Measures of the higher-order moments of skewness (spectral tilt) and kurtosis (peakedness of the spectrum) were included in the present investigation to provide a more complete description of spectral shape (Forrest et al., 1988). Such measures have been used previously to classify voiceless stop and fricative productions (Forrest et al., 1988) and to characterize, in part, the accuracy of consonant place of articulation (Baum and McNutt, 1990; Nittrouer et al., 1989; Waldstein and Baum, 1991). Spectral moments were computed by positioning a 20-ms full Hamming window beginning at the onset of the burst of the stop consonants and at the midpoint of the fricatives in order to capture the attributes of the consonants at a point least affected by vocalic environment.

\section{B. Perceptual analyses}

\section{Subjects}

Ten adult native speakers of (Quebec) French (aged 19-27 years) participated in the perceptual experiments. Listeners were unaware of the purposes of the investigation, were free from speech and/or language disorders, had passed an audiometric screening, and had received no training in phonetic transcription.

\section{Stimuli and procedures}

Isolated vowel and consonant segments (as defined in the acoustic analyses) were used to create six perceptual tests, one for each phoneme class (vowels, stops, fricatives) and subtest (immediate compensation and postconversation). Consonants were presented to listeners isolated from their vowel context in order to avoid any contaminating effects of vowel quality in perceptual judgements. Three productions for each of the 15 speakers in each condition were selected randomly for each of the six tests.

For perceptual judgements, stimuli were presented in random order to listeners via headphones at a comfortable loudness level using the BLISS system. The order of the six perceptual tests was counterbalanced across listeners. Their task was to identify the sound presented from a limited set of alternatives and rate its quality. For example, for the vowel tests, subjects were provided with the choices [a i u] and were instructed to identify which corresponded to the sound they heard. They were then asked to rate the quality of the sound on a five-point scale, with the anchor words being "unintelligible" and "perfect." Stimuli were presented using a 6-s intertrial interval and six practice trials were provided.

\section{RESULTS}

\section{A. Acoustic analyses}

\section{Immediate compensation-Duration measures}

Mean durations for each of the vowel and consonant segments (produced in isolation) were computed and group mean averages are presented in Table II. ${ }^{1}$ Significant differences between conditions, as revealed by statistical comparisons, are indicated. Separate analyses of variance (ANOVAs) were conducted for the three sound types. Details of ANOVA results for the immediate compensation and 
TABLE II. Mean (+s.d.) of the durations (ms) in immediate compensation subtest for vowels, stops, and fricatives in three palate conditions. Values that differ significantly across conditions are indicated between columns.

\begin{tabular}{cccc}
\hline \hline & No palate & Thin palate & Thick palate \\
\hline Vowels & & & \\
{$[\mathrm{u}]$} & $297(57)$ & $302(51)$ & $286(50)$ \\
{$[\mathrm{a}]$} & $272(61)$ & $275(69)$ & $276(59)$ \\
{$[\mathrm{i}]$} & $276(49)$ & $287(57)$ & $289(53)$ \\
Stops & & & \\
{$[\mathrm{p}]$} & $37(10)$ & $38(11)$ & \\
{$[\mathrm{t}]$} & $60(10)$ & $58(12)$ & $38(10)$ \\
{$[\mathrm{k}]$} & $67(11)$ & $72(14)$ & $53(14)$ \\
Fricatives & & & $73(17)$ \\
{$[\mathrm{s}]$} & $232(22)$ & $237(26)$ & $232(29)$ \\
{$[\mathrm{f}]$} & $232(26)$ & $241(24)$ & $239(25)$ \\
\hline \hline
\end{tabular}

postconversation subtests can be found in Appendices A and $\mathrm{B}$, respectively. Only significant differences across conditions will be highlighted.

As can be seen in Table II, for [t], durations in the thick palate condition were significantly shorter than those in the no palate and thin palate conditions which did not differ significantly from one another. For $[\mathrm{k}]$, durations in the thick and thin palate conditions (which did not differ significantly), were significantly longer than those in the no palate condition. ${ }^{2}$

\section{Immediate compensation-Spectral measures}

Group mean values of vowel $F 1$ and $F 2$ calculated at both measurement points are presented in Table III. The ANOVAs revealed that $F 1$ values at onset were significantly higher than those measured at vowel midpoint. As expected, $F 1$ values for [a] were significantly higher than those for [i] and $[\mathrm{u}]$. Also as expected, $F 2$ values for [i] exceeded those of $[\mathrm{a}]$ which in turn exceeded those of $[\mathrm{u}]$. No significant effects of palate condition emerged.

Mean stop and fricative consonant centroid frequencies, skewness, and kurtosis values are presented in Table IV. For $[\mathrm{t}]$, centroid values in the thin palate condition were significantly higher than those in the no palate condition only, indicating a shift in spectral energy concentration to a higher frequency. For $[k]$, centroid values in the thin palate condi- tion were significantly lower than those of the no palate condition. However, it should be noted that this trend for $[\mathrm{k}]$ centroid values was apparent in the data of only 11 of the 15 subjects tested. ${ }^{3}$ In the data of the other four subjects, this pattern was reversed. Kurtosis values for [k] were also significantly lower in the thin and thick palate conditions (which did not differ significantly) than those in the no palate condition. No significant differences across conditions emerged for [p].

For the fricative $[\mathrm{s}]$, centroid values in the thin and thick palate conditions (which did not differ significantly) were significantly lower than those of the no palate condition indicating a shift in the spectral energy concentration to a lower frequency. The skewness and kurtosis values for [s] were also significantly lower in the thin and thick palate conditions (which did not differ) as contrasted to no palate values indicating a less negatively skewed and flatter [s] spectral distribution. No significant differences across conditions were found for [ $]$ ].

\section{Postconversion-Duration measures}

Presented in Table $\mathrm{V}$ are the mean duration values in the no palate and thick palate conditions for the vowel, stop, and fricative stimuli. As illustrated, the presence of the artificial palate had no significant effect on segment durations.

\section{Postconversation-Spectral measures}

Mean $F 1$ and $F 2$ frequencies computed at both measurement points are presented in Table VI, which shows little difference in average $F 1$ or $F 2$ values across conditions, similar to the immediate compensation results. For $[\mathrm{a}]$ and [i], $F 1$ values at onset were significantly higher than those measured at vowel midpoint.

Mean stop and fricative consonant centroid frequencies and skewness and kurtosis values are presented in Table VII. For $[\mathrm{k}]$, skewness values in the thick palate condition were significantly more positively skewed than those of the no palate condition. However, this trend was apparent in the data of only ten of the 15 subjects tested with the reverse pattern apparent in the data of the remaining five subjects. Only two of these five subjects had failed to show the group

TABLE III. Mean (+s.d.) of $F 1$ and $F 2$ frequencies $(\mathrm{Hz})$ at both measurement points in three palate conditions (immediate compensation subtest). Values that differ significantly across conditions are indicated between columns.

\begin{tabular}{|c|c|c|c|c|c|c|}
\hline & \multicolumn{3}{|c|}{ Onset } & \multicolumn{3}{|c|}{ Midpoint } \\
\hline & No palate & Thin palate & Thick palate & No palate & Thin palate & Thick palate \\
\hline$F 1$ & & & & $>^{a}$ & & \\
\hline$[\mathrm{u}]$ & $357(47)$ & $347(43)$ & $345(48)$ & $335(51)$ & $324(51)$ & $327(49)$ \\
\hline [a] & $842(78)$ & $849(41)$ & $852(47)$ & $769(56)$ & $757(80)$ & $764(80)$ \\
\hline [i] & $325(41)$ & $307(56)$ & $324(45)$ & $308(40)$ & $304(43)$ & 298(43) \\
\hline \multicolumn{7}{|l|}{$F 2$} \\
\hline$[\mathrm{u}]$ & $833(106)$ & $805(79)$ & 784(48) & $889(156)$ & 843(104) & $807(84)$ \\
\hline [a] & $1330(137)$ & $1340(141)$ & $1328(130)$ & $1237(130)$ & $1218(138)$ & $1244(125)$ \\
\hline [i] & $2425(221)$ & $2496(153)$ & $2499(138)$ & $2323(286)$ & $2435(198)$ & $2404(171)$ \\
\hline
\end{tabular}

${ }^{a}$ Overall, $F 1$ values were higher when measured at vowel onset as contrasted to midpoint. 
TABLE IV. Mean (+s.d.) of stop and fricative consonant centroid (cent.) frequencies (Hz), skewness (skew.), and kurtosis (kurt.) in three palate conditions (immediate compensation subtest). Values that differ significantly across conditions are indicated between columns.

\begin{tabular}{|c|c|c|c|c|c|}
\hline & & No palate & & Thin palate & Thick palate \\
\hline \multicolumn{6}{|l|}{ Stops } \\
\hline & Cent. & $2696(225)$ & & $2659(187)$ & $2612(267)$ \\
\hline & Skew. & $0.33(0.36)$ & & $0.23(0.25)$ & $0.32(0.27)$ \\
\hline & Kurt. & $0.60(1.14)$ & & $1.05(1.11)$ & $0.66(1.13)$ \\
\hline \multicolumn{6}{|l|}{$[\mathrm{t}]$} \\
\hline & Cent. & $3183(242)$ & $<$ & $3339(268)$ & $3258(229)$ \\
\hline & Skew. & $-0.63(0.30)$ & & $-0.68(0.32)$ & $-0.58(0.26)$ \\
\hline & Kurt. & $0.69(0.89)$ & & $0.79(1.17)$ & $0.25(0.58)$ \\
\hline \multicolumn{6}{|l|}{$[\mathrm{k}]$} \\
\hline & Cent. & 3089(156) & $>$ & $2963(287)$ & $3025(324)$ \\
\hline & Skew. & $-0.17(0.25)$ & & $0.02(0.50)$ & $-0.05(0.44)$ \\
\hline & Kurt. & $3.48(2.46)$ & $>$ & $1.72(2.96)$ & $1.05(1.24)$ \\
\hline \multicolumn{6}{|c|}{$\begin{array}{c}\text { Fricatives } \\
{[\mathrm{s}]}\end{array}$} \\
\hline & Cent. & 7874(671) & $>$ & 7061(770) & 7057(826) \\
\hline & Skew. & $-1.12(0.65)$ & $>$ & $-0.38(0.59)$ & $-0.42(0.67)$ \\
\hline & Kurt. & $3.38(3.5)$ & $>$ & $0.81(0.87)$ & $1.14(1.57)$ \\
\hline \multicolumn{6}{|l|}{$[\mathrm{C}]$} \\
\hline & Cent. & $5045(258)$ & & $4869(435)$ & $5055(470)$ \\
\hline & Skew. & $0.55(0.27)$ & & $0.69(0.35)$ & $0.61(0.42)$ \\
\hline & Kurt. & $0.75(0.69)$ & & $1.64(1.13)$ & $1.63(1.63)$ \\
\hline
\end{tabular}

pattern in the immediate compensation condition. Kurtosis values for $[\mathrm{k}]$ were also significantly lower (indicating a flatter spectral distribution) in the thick palate as contrasted to the no palate condition. For [s], centroid values in the thick palate condition were significantly lower than those of the no palate condition indicating a shift in spectral energy concentration to lower frequencies. The skewness and kurtosis values for [s] were also significantly lower in the thick palate as contrasted to the no palate condition characterizing a less negatively skewed and flatter [s] spectral distribution. The trend for kurtosis was present in the data of only 11 of the 15 subjects, and the reverse pattern was seen in the data of the other four subjects. Only one of these four subjects was the same as those who failed to show the group pattern in either the immediate compensation condition for $[\mathrm{k}]$ kurtosis or

TABLE V. Mean (+s.d.) of durations (ms) in the postconversation subtest for vowels, stops, and fricatives in two palate conditions. Values that differ significantly across conditions are indicated between columns.

\begin{tabular}{lcc}
\hline \hline & No palate & Thick palate \\
\hline Vowels & & \\
{$[\mathrm{u}]$} & $278(56)$ & $278(48)$ \\
{$[\mathrm{a}]$} & $259(47)$ & $262(47)$ \\
{$[\mathrm{i}]$} & $270(65)$ & $278(58)$ \\
Stops & & \\
{$[\mathrm{p}]$} & $36(8)$ & $36(9)$ \\
{$[\mathrm{t}]$} & $62(11)$ & $58(11)$ \\
{$[\mathrm{k}]$} & $66(9)$ & $71(12)$ \\
Fricatives & & \\
{$[\mathrm{s}]$} & $231(21)$ & $232(26)$ \\
{$[\mathrm{S}]$} & $227(21)$ & $235(29)$ \\
\hline \hline
\end{tabular}

1097 J. Acoust. Soc. Am., Vol. 100, No. 2, Pt. 1, August 1996 postconversation condition for [k] skewness. No other consonantal attributes were affected by the palatal appliance.

\section{B. Perceptual analyses}

\section{Immediate compensation}

Overall means for percent correct identification and quality ratings for the immediate compensation and postconversation subtests are presented in Figs. 1 and 2, respectively. Separate analyses of variance (ANOVAs) were computed for identification responses and quality ratings for each of the three sound classes. ${ }^{4}$ (See Appendices C and D for details.)

As illustrated in Fig. 1(a), identification accuracy was quite high across vowels and palate conditions. Statistical analyses did, however, reveal a significant vowel by condi

TABLE VI. Mean (+s.d.) of $F 1$ and $F 2$ frequencies (Hz) at both measurement points in two palate conditions (post conversation subtest). Values that differ significantly across conditions are indicated between columns.

\begin{tabular}{lrrrrrr}
\hline \hline & \multicolumn{2}{c}{ Onset } & & \multicolumn{2}{c}{ Midpoint } \\
\cline { 2 - 3 } \cline { 5 - 6 } & No palate & Thick palate & & No palate & Thick palate \\
\hline$F 1$ & & & & & \\
{$[\mathrm{u}]$} & $333(38)$ & $333(28)$ & & $302(30)$ & $300(25)$ \\
{$[\mathrm{a}]$} & $840(33)$ & $846(71)$ & $>$ & $766(79)$ & $779(60)$ \\
{$[\mathrm{i}]$} & $327(39)$ & $312(25)$ & & $286(32)$ & $285(27)$ \\
$F 2$ & & & & & \\
{$[\mathrm{u}]$} & $812(133)$ & $801(65)$ & & $905(229)$ & $832(162)$ \\
{$[\mathrm{a}]$} & $1321(176)$ & $1309(155)$ & & $1239(163)$ & $1246(175)$ \\
{$[\mathrm{i}]$} & $2406(225)$ & $2352(253)$ & & $2380(186)$ & $2289(208)$ \\
\hline \hline
\end{tabular}



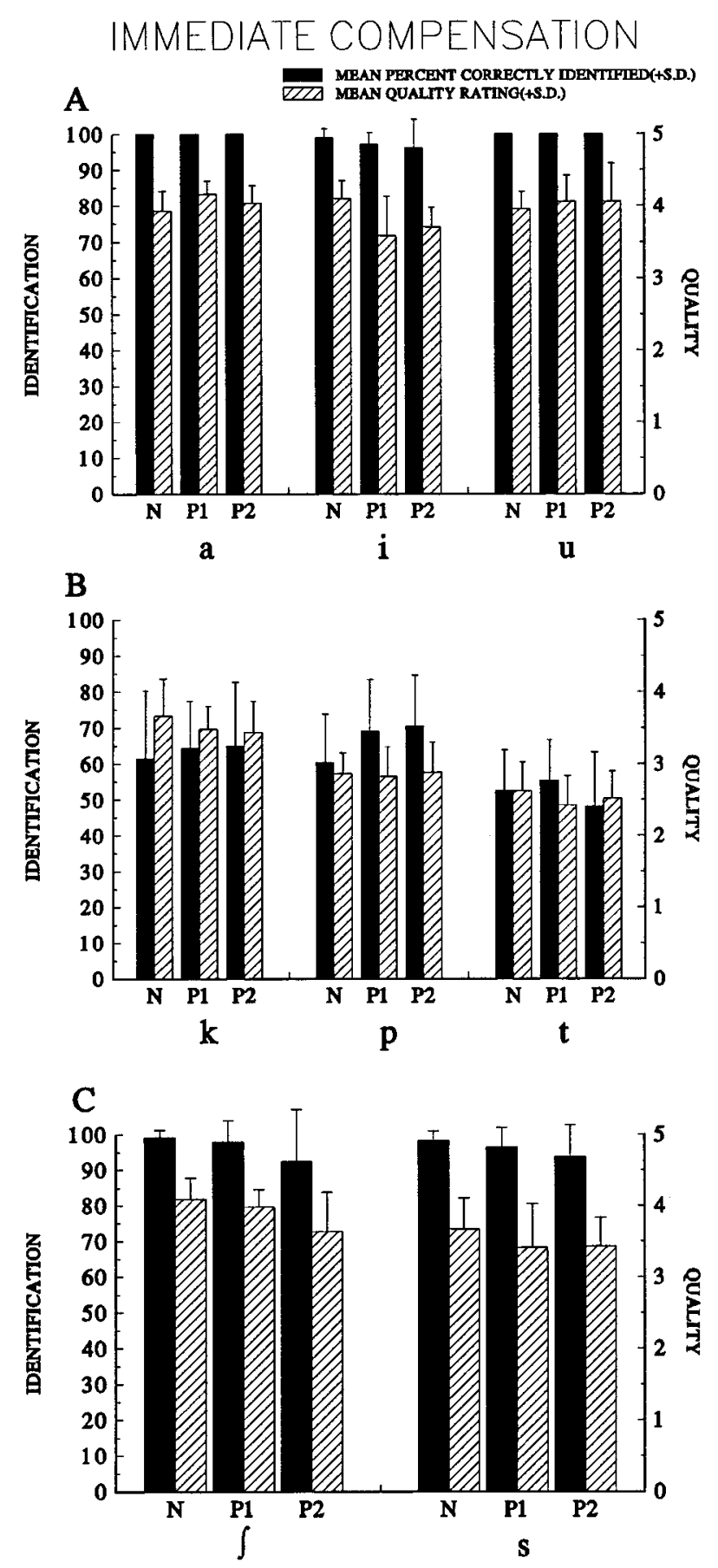

FIG. 1. Mean percent correct identification and quality ratings for the immediate compensation subtest. A: vowels, B: stops, C: fricatives. Palate conditions, N: no palate, P1: thin palate, $\mathrm{P} 2$ : thick palate.

tion interaction for vowel quality ratings. Newman-Keuls post-hoc analyses revealed significantly higher quality ratings for [i] in the no palate as contrasted to the thin and thick palate conditions, which did not differ. No other significant differences were found between conditions for the other two vowels.

It may be seen from Fig. 1(b) that identification accuracy tended to be lower for stop consonants when contrasted with vowels [and fricatives, Fig. 1(c)]. As also apparent in Fig. 1(b), no significant effect of condition was observed in stop quality ratings. Identification responses varied across
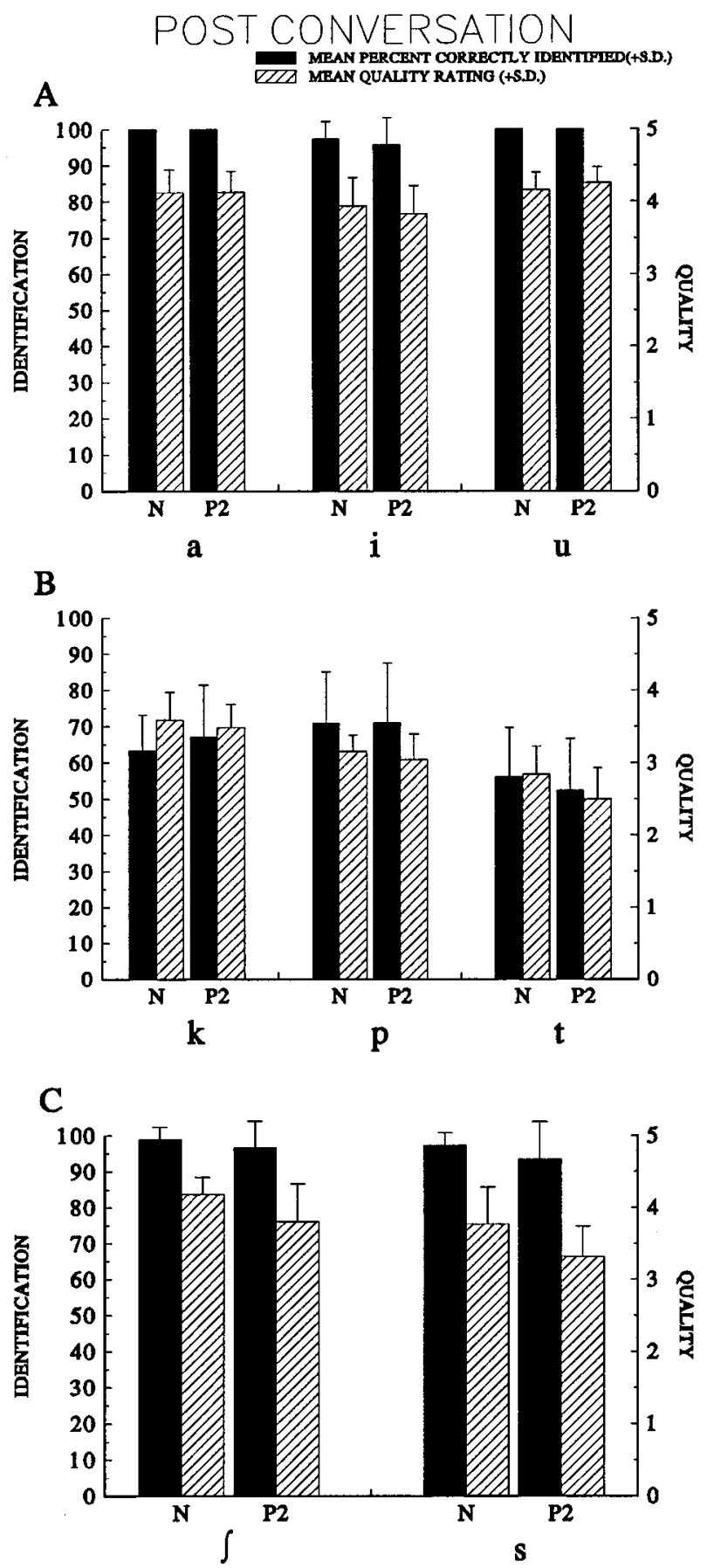

FIG. 2. Mean percent correct identification and quality ratings for the postconversation subtest. A: vowels, B: stops, C: fricatives. Palate conditions $-\mathrm{N}$ : no palate, $\mathrm{P} 2$ : thick palate.

stops and palate conditions, with the lowest identification accuracy evident for [t]. Confusion matrices for stops are presented in Table VIII. As can be seen, [t] was most often misidentified as $[\mathrm{p}]$, while $[\mathrm{k}]$ and $[\mathrm{p}]$ were most often misperceived as $[\mathrm{t}]$.

As illustrated in Fig. 1(c), percent correct identification and quality ratings for fricatives tended to be lower in the artificial palate conditions, and significant main effects of condition were found for both measures. Post-hoc analyses of identification and quality ratings revealed significant differences among all three conditions, with the best perfor- 
TABLE VII. Mean (+s.d.) of stop fricative consonant centroid (cent.) frequencies (Hz), skewness (skew.), and kurtosis (kurt.) in two palate conditions (postconversation subtest). Values that differ significantly across conditions are indicated between columns.

\begin{tabular}{|c|c|c|c|c|}
\hline & & No palate & & Thick palate \\
\hline \multicolumn{5}{|l|}{ Stops } \\
\hline & Cent. & $2648(284)$ & & $2677(275)$ \\
\hline & Skew. & $0.37(0.26)$ & & $0.19(0.21)$ \\
\hline & Kurt. & $0.14(0.90)$ & & $0.16(0.49)$ \\
\hline \multicolumn{5}{|l|}{$[\mathrm{t}]$} \\
\hline & Cent. & $3221(236)$ & & 3219(181) \\
\hline & Skew. & $-0.71(0.36)$ & & $-0.53(0.24)$ \\
\hline & Kurt. & $0.85(0.93)$ & & $0.29(0.72)$ \\
\hline \multicolumn{5}{|c|}{$[\mathrm{k}]$} \\
\hline & Cent. & $3130(211)$ & & $2985(338)$ \\
\hline & Skew. & $-0.22(0.35)$ & $>$ & $0.02(0.44)$ \\
\hline & Kurt. & $3.05(2.43)$ & $>$ & $1.07(1.40)$ \\
\hline \multicolumn{5}{|c|}{ Fricatives } \\
\hline & Cent. & $7655(762)$ & $>$ & $7065(860)$ \\
\hline & Skew. & $-0.86(0.61)$ & $>$ & $-0.47(0.60)$ \\
\hline & Kurt. & $2.65(2.64)$ & $>$ & $0.86(1.36)$ \\
\hline & Cent. & $4968(431)$ & & 4912(490) \\
\hline & Skew. & $0.63(0.41)$ & & $0.64(0.52)$ \\
\hline & Kurt. & $1.06(1.19)$ & & $1.65(1.43)$ \\
\hline
\end{tabular}

mance in the no palate condition followed by the thin and thick palate conditions.

\section{Postconversation}

As revealed in Fig. 2(a) and similar to the results of the immediate compensation subtest, percent correct identification of vowels in the postconversation condition was overall very high and varied little across palate conditions. And,

TABLE VIII. Confusion matrices for stops: Immediate compensation condition.

\begin{tabular}{lcccc}
\hline \hline & & No palate & \\
& & \multicolumn{3}{c}{ Sound produced } \\
\cline { 3 - 5 } & & {$[\mathrm{p}]$} & {$[\mathrm{t}]$} & {$[\mathrm{k}]$} \\
Sound & {$[\mathrm{p}]$} & $60 \%$ & $36 \%$ & $8 \%$ \\
identified & {$[\mathrm{t}]$} & $32 \%$ & $52 \%$ & $31 \%$ \\
& {$[\mathrm{k}]$} & $8 \%$ & $12 \%$ & $61 \%$ \\
& & Thin palate & & \\
& & & Sound produced & \\
\cline { 2 - 4 } & & {$[\mathrm{p}]$} & {$[\mathrm{t}]$} & {$[\mathrm{k}]$} \\
Sound & & $69 \%$ & $34 \%$ & $10 \%$ \\
identified & {$[\mathrm{p}]$} & $22 \%$ & $55 \%$ & $26 \%$ \\
& {$[\mathrm{t}]$} & $9 \%$ & $11 \%$ & $64 \%$ \\
& {$[\mathrm{k}]$} & & & \\
& & Thick palate & Sound produced & \\
& & & {$[\mathrm{t}]$} & {$[\mathrm{k}]$} \\
Sound & & {$[\mathrm{p}]$} & $42 \%$ & $9 \%$ \\
identified & {$[\mathrm{p}]$} & $71 \%$ & $48 \%$ & $26 \%$ \\
& {$[\mathrm{t}]$} & $21 \%$ & $10 \%$ & $65 \%$ \\
\hline \hline
\end{tabular}

TABLE IX. Confusion matrices for stops: Postconversation condition.

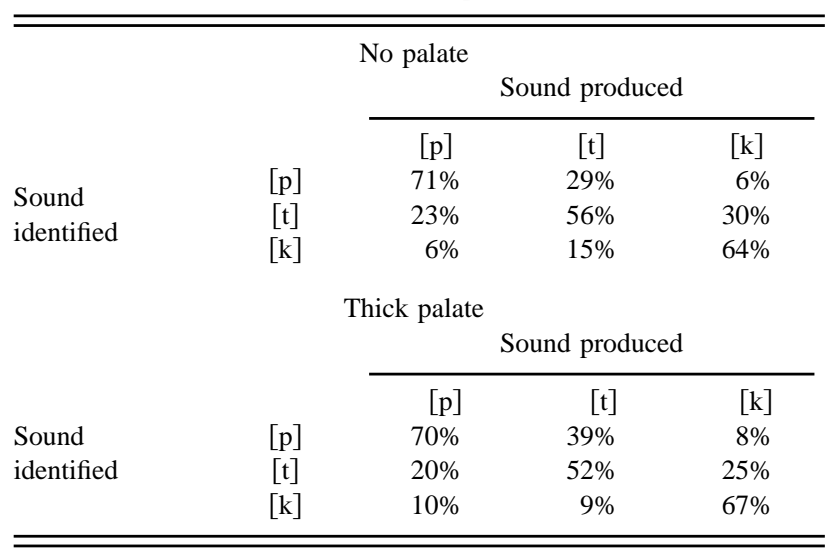

unlike the immediate compensation subtest, vowel quality was not significantly affected by the presence of the artificial palate for any of the vowels.

As demonstrated in Fig. 2(b), identification accuracy and quality tended to be lower overall for stops when contrasted to both vowels and fricatives [Fig. 2(c)] as in the immediate compensation condition. Identification scores for stops varied considerably, and no significant differences in patterns emerged. Confusion matrices for stops are presented in Table IX. Again, [k] and [p] were most often misperceived as [t], which in turn was most often misidentified as [p]. Quality ratings tended to be lower in the thick palate as contrasted to the no palate condition, as indicated by the statistical results.

Means of identification scores and quality ratings for fricatives are presented in Fig. 2(c). Unlike the immediate compensation condition, no significant effect of condition was found for identification accuracy. In contrast, quality ratings tended to be lower in the thick palate as contrasted to the no palate condition for both fricatives, as in the immediate compensation subtest.

\section{DISCUSSION}

Probably the most striking difference between our earlier bite-block results and those of the present investigation was the fact that virtually no significant differences were found in the acoustic and perceptual parameters of vowels produced under normal and palate conditions. ${ }^{5}$ The only significant effects were subtle and involved differences in quality ratings of the vowel [i] in the immediate compensation condition only. These data are generally consistent with those of previous investigators exploring the effects of artificial palates on vowel production (Garber et al., 1980; but see Hamlet and Stone, 1976b). Although there were few differences in the present study, our earlier experimental data revealed that the presence of a bite block is significantly perturbing to vowel production and adequate compensatory articulation is neither immediate nor complete. Instead, a period of adaptation is necessary for the development of compensatory strategies (McFarland and Baum, 1995). Not surprisingly, a fixed jaw opening is relatively more perturbing to vowel production than the presence of an artificial palate. Clearly the jaw is free to move in the case of the artificial palate and our data suggest that a new vocal tract configuration appropriate for the change in oral form is rapidly 
achieved. It has been shown previously that increases in jawopening and velocity accompany speech adaptation to artificial palates (Hamlet et al., 1978).

In marked contrast to vowels, production of the fricative [s] appears to be highly susceptible to the perturbing effects of the artificial palate. ${ }^{6}$ These data are consistent with previous clinical observations and experimental results suggesting that sibilants are selectively impaired by the presence of dental appliances (Garber et al., 1980; Hamlet, 1973; Palmer, 1979). Temporary fixation of the jaw with a bite block also adversely affects sibilant production (McFarland and Baum, 1995), suggesting that both types of modifications of the vocal tract perturb sibilants perhaps because this sound class requires greater articulatory precision than others (StoelGammon and Dunn, 1985; see also Fletcher and Newman, 1991). That is, sibilants are among the last sounds to be acquired in speech development presumably due in part to the complexity of the articulatory gestures required [e.g., a particular groove shape for [s] production (Flege et al., 1988)]. Sibilants are also among the sounds most susceptible to breakdowns in production for similar reasons (Prather et al., 1975; Stoel-Gammon and Dunn, 1985). In addition, particularly as contrasted to the three "point" vowels tested in the present study, small changes in sibilant articulation may yield more significant acoustic changes that are perceptually salient. It has been shown that the acoustics of the point vowels, in contrast, are particularly resistant to small changes in articulation (Stevens, 1972).

In the present study, lower centroid, skewness, and kurtosis values were found for $[\mathrm{s}]$ in palate as contrasted to no palate conditions for both the immediate and postconversation subtests. These spectral changes may represent significant differences in lingual articulatory configuration for [s] and/or the aerodynamics of fricative production under conditions of perturbation. Reductions in tongue groove width and tongue overshoot during fricative production with an artificial palate in place have been previously reported (Hamlet and Stone, 1978). The present acoustic findings were supported by perceptual results as identification accuracy and quality ratings were significantly lower for both fricatives in palate versus normal conditions in the immediate compensation subtest. Although quality ratings were significantly lower under conditions of perturbation for both fricatives in the postconversation subtest, no significant effect of condition was observed for identification accuracy. This may indicate that compensatory strategies are developing during the short period of practice with the palate in place. Recall that the 15-min adaptation period was chosen to allow for comparisons to our previous bite-block data. Previous results have revealed that artificial palates may require a lengthy adaptation period, perhaps involving days or weeks, before normal speech is approached (Hamlet and Stone, 1974). It would be useful, therefore, to study sibilant production under conditions of perturbation over a much longer time frame to ascertain both the nature of the compensatory process and the time required for various aspects of compensation to occur.

Although some evidence of the perturbing effects of the artificial palate on the acoustic parameters of stops were found in the results of both the immediate and post conversation subtests, we hesitate to draw firm conclusions because the data are complex and difficult to interpret. Further, there were no differences in stop identification or quality ratings across experimental conditions in either the immediate compensation or postconversation subtest. Recall, however, that isolated stops were presented to listeners for perceptual judgements, and acoustic differences may not have been detected in the very short duration stimuli. Moreover, the identification of voiceless stop consonants extracted from different vowel environments may be influenced by coarticulatory “smear" (Winitz et al., 1972). Such effects would decrease correct identification rates overall, possibly rendering the task less sensitive to effects of condition. We tentatively conclude that stops fall somewhere between vowels and fricatives in terms of their susceptibility to structural modifications of the oral environment. This interpretation is in general agreement with previous investigations of the effects of artificial palates and dental prostheses on speech production (Garber et al., 1980; Hamlet, 1973).

One of the more confusing findings for stops was that spectral differences were found only between the thin and no palate conditions in the immediate compensation subtest. One possible explanation is that it is more difficult to adapt to the subtle changes in palatal contour associated with the thin palate because approximately the same articulatory positioning as in the absence of the palate could be attempted. The thick palate may require a radically different articulatory configuration than normal and consequently this articulatory perturbation may "force" the development of compensatory strategies. It is interesting to note that even very thin artificial palates (e.g., 1 or $1.5 \mathrm{~mm}$ ) may result in speech sound errors (Garber et al., 1980, Hamlet and Stone, 1978).

Consistent with previous experiments, there appeared to be individual variability in compensatory abilities (Flege et al., 1988; McFarland and Baum, 1995). In a recent experiment, Savariaux et al. (1995) studied compensatory vowel articulation (French vowel [u]) to altered lip constriction area (a Plexiglas tube was held between the lips). Vocal tract configuration including tongue shape and constriction location was measured using teleradiography. Results revealed that individual subjects differed significantly in their ability to compensate to the oral-articulatory perturbation, and only one subject showed complete compensation in the form of appropriate $F 1-F 2$ values and posterior compensatory tongue positioning. Seven subjects compensated only partially, and four of the subjects demonstrated no compensation to the change in oral form. The authors suggest that individual speakers may differ globally in their articulatory "skill" and the ability to utilize sensory information in assessing the acoustic consequences of altered vocal tract configuration (Savariaux et al., 1995). We provided a similar interpretation of our earlier finding of individual differences in speech compensatory abilities to increased jaw opening (McFarland and Baum, 1995). It is interesting to note that individual speakers have been found to differ in their capacity to systematically alter sibilant groove shapes in response to specific feedback, suggesting that even with intentional control, some speakers may be unable to adapt completely to 
an articulatory pertubation (Fletcher and Newman, 1991). Further investigations involving the simultaneous recording of both acoustic and articulatory-kinematic variables under conditions of perturbation are likely to provide important insights into mechanisms underlying individual compensatory abilities.

\section{SUMMARY}

Taken together, the findings of the present investigation and those of our previous bite-block studies can be summarized as follows. First, our results suggest that there are significant acoustic and perceptual differences between normal vowel and/or consonant productions and those articulated under certain conditions of perturbation. Second, speech compensation for at least a subset of speech sounds appears to improve over time, and these data support a role for sensory feedback in the adaptation of articulatory gestures (McFarland and Baum, 1995). Third, the patterns of compensation to bite blocks and artificial palates differ. For example, a fixed jaw opening appears to be relatively more perturbing to vowel production than the presence of an artificial palate. Finally, speech sounds of different phoneme classes may be differentially impaired by the presence of a perturbation. Sibilants appear to be particularly susceptible to the perturbations we have examined. In future investigations, it will be important to consider in detail the effects of any particular perturbation on the articulatory requirements of specific sound production.

\section{ACKNOWLEDGMENTS}

We would like to thank M. Diab, P.-A. Ménard, and L. Schumacher for their assistance in data collection and analysis. Thanks also to Dr. Sophie Emmell who assisted in occlusal and palatal evaluations and the fabrication and insertion of the artificial palates. Comments by the editor and two anonymous reviewers are very much appreciated. This work was supported by grants from the Fonds de la recherche en santé du Québec.

\section{APPENDIX A}

TABLE AI. Acoustic analyses, significant ANOVA results, immediate compensation condition. V=vowel, $\mathrm{S}=$ stop, $\mathrm{F}=$ fricative, meas. $=$ measurement point, cond. $=$ condition .

\begin{tabular}{|c|c|c|}
\hline & Main effects & Interactions \\
\hline \multicolumn{3}{|l|}{ Duration } \\
\hline \multicolumn{3}{|l|}{$\mathrm{V} X$ condition } \\
\hline $\mathrm{S} X$ condition & $S: F(2,28)=89.311, p<0.001$ & S X cond.: $F(4,56)=7.125, p<0.05$ \\
\hline \multicolumn{3}{|l|}{ F X condition } \\
\hline \multicolumn{3}{|l|}{ Vowel $F 1$} \\
\hline \multirow[t]{2}{*}{ Meas. X V X condition } & meas.: $F(1,5)=9.571, p<0.05$ & \\
\hline & $\mathrm{V}: F(2,10)=570.310, p<0.001$ & \\
\hline \multicolumn{3}{|l|}{ Vowel $F 2$} \\
\hline Meas. X V X condition & $\mathrm{V}: F(2,12)=834.600, p<0.001$ & \\
\hline \multicolumn{3}{|l|}{ Stop centroid } \\
\hline $\mathrm{S} X$ condition & $\mathrm{S}: F(2,28)=63.637, p<0.001$ & S X cond.: $F(4,56)=4.870, p<0.05$ \\
\hline \multicolumn{3}{|l|}{ Stop skewness } \\
\hline $\mathrm{S} X$ condition & $\mathrm{S}: F(2,28)=51.132, p<0.001$ & \\
\hline \multicolumn{3}{|l|}{ Stop kurtosis } \\
\hline $\mathrm{S} X$ condition & $\begin{array}{l}\mathrm{S}: F(2,28)=6.948, p<0.05 \\
\text { cond.: } F(2,28)=7.507, p<0.05\end{array}$ & S X cond.: $F(4,56)=5.601, p<0.05$ \\
\hline \multicolumn{3}{|l|}{ Fricative centroid } \\
\hline F X condition & $\begin{array}{l}\mathrm{F}: F(1,14)=144.983, p<0.001 \\
\text { cond.: } F(2,28)=27.955, p<0.001\end{array}$ & F X cond.: $F(2,28)=19.746, p<0.001$ \\
\hline \multicolumn{3}{|l|}{ Fricative skewness } \\
\hline F X condition & $\begin{array}{l}\mathrm{F}: F(1,14)=49.698, p<0.001 \\
\text { cond.: } F(2,28)=18.525, p<0.001\end{array}$ & F X cond.: $F(2,28)=8.507, p<0.05$ \\
\hline \multicolumn{3}{|l|}{ Fricative kurtosis } \\
\hline F X condition & cond.: $F(2,28)=3.473, p<0.05$ & F X cond.: $F(2,28)=11.473, p<0.001$ \\
\hline
\end{tabular}


TABLE BI. Acoustic analyses, significant ANOVA results, postconversation condition. Legend: V=vowel, $\mathrm{S}=$ stop, $\mathrm{F}=$ fricative, meas. $=$ measurement point, cond. $=$ condition.

\begin{tabular}{|c|c|c|}
\hline & Main effects & Interactions \\
\hline $\begin{array}{l}\text { Duration } \\
\text { V X condition } \\
\text { S X condition } \\
\text { F X condition }\end{array}$ & $\begin{array}{l}\text { V: } F(2,28)=4.674, p<0.05 \\
\text { S: } F(2,28)=123.881, p<0.001\end{array}$ & \\
\hline $\begin{array}{l}\text { Vowel } F 1 \\
\text { Meas. X V X condition }\end{array}$ & $\begin{array}{l}\text { meas.: } F(1,8)=11.911, p<0.05 \\
\text { V: } F(2,16)=589.480, p<0.001\end{array}$ & meas. X V: $F(2,16)=6.101, p<0.05$ \\
\hline $\begin{array}{l}\text { Vowel } F 2 \\
\text { Meas. X V X condition }\end{array}$ & $\mathrm{V}: F(2,14)=178.229, p<0.001$ & \\
\hline $\begin{array}{l}\text { Stop centroid } \\
\text { S X condition }\end{array}$ & $\mathrm{S}: F(2,28)=42.881, p<0.001$ & \\
\hline $\begin{array}{l}\text { Stop skewness } \\
\text { S X condition }\end{array}$ & $\mathrm{S}: F(2,28)=50.818, p<0.001$ & S X cond.: $F(2,28)=4.978, p<0.05$ \\
\hline $\begin{array}{l}\text { Stop kurtosis } \\
\text { S X condition }\end{array}$ & $\begin{array}{l}\text { S: } F(2,28)=11.722, p<0.001 \\
\text { cond.: } F(1,14)=33.588, p<0.001\end{array}$ & S X cond.: $F(2,28)=11.407, p<0.001$ \\
\hline $\begin{array}{l}\text { Fricative centroid } \\
\text { F X condition }\end{array}$ & $\begin{array}{l}\mathrm{F}: F(1,14)=125.517, p<0.001 \\
\text { cond.: } F(1,14)=19.874, p<0.05\end{array}$ & F X cond.: $F(1,14)=14.925, p<0.05$ \\
\hline $\begin{array}{l}\text { Fricative skewness } \\
\text { F X condition }\end{array}$ & $\begin{array}{l}\text { F: } F(1,14)=39.764, p<0.001 \\
\text { cond.: } F(1,14)=5.057, p<0.05\end{array}$ & F X cond.: $F(1,14)=5.071, p<0.05$ \\
\hline $\begin{array}{l}\text { Fricative kurtosis } \\
\text { F X condition }\end{array}$ & cond.: $F(1,14)=10.477, p<0.005$ & $\mathrm{~F} X$ cond.: $F(1,14)=7.392, p<0.05$ \\
\hline
\end{tabular}

\section{APPENDIX C}

TABLE CI. Perceptual analyses, significant ANOVA results, immediate compensation condition. Legend: $\mathrm{V}=$ vowel, $\mathrm{S}=$ stop, $\mathrm{F}=$ fricative, cond.=condition.

\begin{tabular}{|c|c|c|}
\hline & Main effects & Interactions \\
\hline $\begin{array}{l}\text { Percent correctl } \\
\text { Vowel } \\
\text { V X condition }\end{array}$ & & \\
\hline $\begin{array}{l}\text { Stop } \\
\text { S X condition }\end{array}$ & $\mathrm{S}: F(2,28)=12.558, p<0.001$ & \\
\hline $\begin{array}{l}\text { Fricative } \\
\text { F X condition }\end{array}$ & cond.: $F(2,28)=4.885, p=0.015$ & \\
\hline $\begin{array}{l}\text { Quality } \\
\text { Vowel } \\
\text { V X condition }\end{array}$ & $\mathrm{V}: F(2,28)=9.824, p=0.001$ & $\mathrm{VX}$ cond.: $F(4,52)=7.755, p<0.001$ \\
\hline $\begin{array}{l}\text { Stop } \\
\text { S X condition }\end{array}$ & $\mathrm{S}: F(2,28)=76.622, p<0.001$ & \\
\hline $\begin{array}{l}\text { Fricative } \\
\text { F X condition }\end{array}$ & $\begin{array}{l}\mathrm{F}: F(1,14)=25.279, p<0.001 \\
\text { cond.: } F(2,28)=16.426, p<0.001\end{array}$ & \\
\hline
\end{tabular}




\section{APPENDIX D}

TABLE DI. Perceptual analyses, significant ANOVA results, postconversation condition. Legend: $\mathrm{V}=$ vowel, $\mathrm{S}=$ stop, $\mathrm{F}=$ fricative, cond.=condition.

\begin{tabular}{|c|c|c|}
\hline & Main effects & Interactions \\
\hline $\begin{array}{l}\text { Percent correctly } \\
\text { Vowel } \\
\text { V X condition }\end{array}$ & & \\
\hline $\begin{array}{l}\text { Stop } \\
\text { S X condition }\end{array}$ & $\mathrm{S}: F(2,28)=9.166, p=0.001$ & \\
\hline $\begin{array}{l}\text { Fricative } \\
\text { F X condition }\end{array}$ & & \\
\hline $\begin{array}{l}\text { Quality } \\
\text { Vowel }\end{array}$ & & \\
\hline $\mathrm{V} X$ condition & $\mathrm{V}: F(2,28)=16.389, p<0.001$ & \\
\hline $\begin{array}{l}\text { Stop } \\
\text { S X condition }\end{array}$ & $\begin{array}{l}\text { S: } F(2,28)=50.139, p<0.001 \\
\text { cond.: } F(1,14)=4.746, p=0.047\end{array}$ & \\
\hline $\begin{array}{l}\text { Fricative } \\
\text { F X condition }\end{array}$ & $\begin{array}{l}\mathrm{F}: F(1,14)=51.150, p<0.001 \\
\text { cond.: } F(1,14)=37.446, p<0.001\end{array}$ & \\
\hline
\end{tabular}

${ }^{1}$ These VOT values correspond well with those previously found in studies of Québec French (Jacques, 1983).

${ }^{2}$ As suggested by one reviewer, increased airflow resistance following consonantal release and a delay in transglottal pressure drop suitable for voicing may have contributed to differences in $[\mathrm{k}]$ duration under conditions of perturbation. The duration results for [t], however, indicate the reverse pattern with shorter durations found under conditions of perturbation.

${ }^{3}$ Unless otherwise noted, other group trends were apparent in the data of at least 13 of the 15 subjects tested.

${ }^{4}$ ANOVAs were computed both by speaker and by listener. To be conservative, we will report only those differences that were significant in both analyses.

${ }^{5}$ There is a remote possibility that, by setting range limitations for the vowel formant frequencies we made the measures less sensitive to extreme (outlier) errors of production (such a procedure was not undertaken for measures of consonants). However, the same vowel formant screen was utilized in our previous bite block study in which significant effects of the perturbation emerged. Therefore, it seems unlikely that differences across conditions were obscured in the analysis.

${ }^{6}$ Because the same acoustic measures cannot be made for vowels and consonants, it is possible that the spectral measures computed for consonants were more sensitive than those computed for vowels. However, the perceptual data support the claim based on acoustic analyses that the presence of the artificial palate was more detrimental to fricatives than vowels.

Abbs, J. H., and Gracco, V. L. (1984). "Control of complex motor gestures: Orofacial muscle responses to load perturbations of lip during speech," J. Neurophysiol. 51, 705-723.

Allen, L. R. (1958). "Improved phonetics in denture construction,' J. Prosthet. Dent. 8, 753-763.

Baum, S. R., and Katz, W. F. (1988). "Acoustic analysis of compensatory articulation in children," J. Acoust. Soc. Am. 84, 1662-1668.

Baum, S. R., and McNutt, J. C. (1990). "An acoustic analysis of frontal misarticulation of /s/ in children," J. Phon. 18, 51-63.

Baum, S. R., McFarland, D. H., and Diab, M. (1996). "Compensation to articulatory perturbation: Perceptual data,' J. Acoust. Soc. Am. 99, 37913794.

Chaney, S. A., Moller, K. T., and Goodkind, R. J. (1978). "Effects of immediate dentures on certain structural and perceptual parameters of speech," J. Prosthet. Dent. 40, 8-12.

Chierici, G., and Lawson, L. (1973). "Clinical speech considerations in prosthodontics: Perspectives of the prosthodontist and speech pathologist," J. Prosthet. Dent. 29, 29-39.
Delattre, P. (1966). Studies in French and Comparative Phonetics (Mouton, The Hague).

Flege, J. E., Fletcher, S. G., and Homiedan, A. (1988). "Compensating for a bite block in /s/ and /t/ production: Palatographic, acoustic, and perceptual data," J. Acoust. Soc. Am. 83, 212-228.

Fletcher, S. G., and Newman, D. G. (1991). "[s] and [s] as a function of linguapalatal contact place and sibilant groove width," J. Acoust. Soc. Am. 89, 850-858.

Folkins, J., and Zimmermann, G. N. (1982). "Lip and jaw interaction during speech: Responses to perturbation of lower-lip movement prior to bilabial closure," J. Acoust. Soc. Am. 71, 1225-1233.

Forrest, K., Weismer, G., Milenkovic, P., and Dougall, R. (1988). "Statistical analysis of word-initial voiceless obstruents: Preliminary data," J. Acoust. Soc. Am. 84, 115-123.

Fowler, C. A., and Turvey, M. T. (1980). "Immediate compensation in bite-block speech," Phonetica 37, 306-326.

Garber, S. R., Speidel, T. M., Siegel, G. M., Miller, E., and Glass, L. (1980). "The effects of presentation of noise and dental appliances on speech," J. Speech Hear. Res. 23, 838-852.

Gay, T., Lindblom, B., and Lubker, J. (1981). "Production of bite-block vowels: Acoustic equivalence by selective compensation,' J. Acoust. Soc. Am. 69, 802-810.

Gracco, V. L., and Abbs, J. H. (1988). "Central patterning of speech movement timing," Exp. Brain Res. 71, 515-526.

Hamlet, S., and Stone, M. (1974). "Reorganization of speech motor patterns following prosthodontic changes in oral morphology,"' Speech Commun. Seminar 2, 79-86.

Hamlet, S. L., and Stone, M. (1976a). " Observations on speech preparatory activity of the jaw in natural and compensatory speech,' J. Acoust. Soc. Am. 59, S58.

Hamlet, S. L., and Stone, M. (1976b). "Compensatory vowel characteristics resulting from the presence of different types of experimental dental prostheses,' J. Phon. 4, 199-218.

Hamlet, S., Stone, M., and McCarty, T. (1978). "Conditioning prostheses viewed from the standpoint of speech adaptation," J. Prosthet. Dent. 40, $60-66$.

Hamlet, S. L. (1973). "'Speech adaptation to dental appliances: Theoretical considerations," J. Baltimore Coll. Dent. Surg. 28, 52-63.

Hamlet, S. L. and Stone, M. (1978). "Compensatory alveolar consonant production induced by wearing a dental prosthesis," J. Phon. 6, 227-248.

Hamlet, S. L., Cullison, B. L., and Stone, M. L. (1979). "Physiological control of sibilant duration: Insights afforded by speech compensation to dental prostheses," J. Acoust. Soc. Am. 65, 1276-1285.

Jacques, B. (1983). "Étude acoustique des consonnes du Français parlé: Analyse spectral, intensité, durée,' unpublished doctoral dissertation, Université de Montréal.

Kelso, J. A. S., and Tuller, B. (1983). “Compensatory articulation under conditions of reduced afferent information: a dynamic formulation," $\mathrm{J}$. Speech Hear. Res. 26, 217-224.

Kelso, J. A. S., Tuller, B., Vatikiotis-Bateson, E., and Fowler, C. A. (1984). "Functionally specific articulatory adaptation to jaw perturbations during speech: Evidence for coordinative structures," J. Exp. Psychol. 10, 812832.

Kent, R. D., Martin, R. E., and Sufit, R. L. (1990). "Oral sensation: A review and clinical prospective," in Human Communication and Its Disorders, A Review 1990, edited by H. Winitz (Ablex, Norwood), pp. 135191.

Lindblom, B. E. F., and Sundberg, J. E. F. (1971). "Acoustical consequences of lip, tongue, jaw, and larynx movement," J. Acoust. Soc. Am. 50, 1166-1179.

Lindblom, B., Lubker, J., and Gay, T. (1979). "Formant frequencies of some fixed-mandible vowels and a model of speech motor programming by predictive simulation," J. Phon. 7, 147-161.

McFarland, D. H., and Baum, S. R. (1995). "Incomplete compensation to articulatory perturbation,” J. Acoust. Soc. Am. 97, 1865-1873.

McFarland, D. H., and Lund, J. P. (1995). "The control of speech," in Studies in Physiology, Vol. 3-Neural Control of Skilled Human Movement, edited by F. W. J. Cody (Portland, London), pp. 61-74.

Munhall, K. G., Löfqvist, A., and Kelso, J. A. S. (1994). "Lip-larynx coordination in speech: Effects of mechanical perturbations to the lower lip," J. Acoust. Soc. Am. 95, 3605-3616.

Nittrouer, S., Studdert-Kennedy, M., and McGowan, R. S. (1989). "The emergence of phonetic segments: Evidence from the spectral structure of fricative-vowel syllables spoken by children and adults," J. Speech Hear. Res. 32, 120-132. 
Palmer, J. M. (1979). "'Structural changes for speech improvement in complete upper denture fabrication," J. Prosthet. Dent. 41, 507-510.

Peterson, G. E., and Barney, H. L. (1952). "Control methods used in a study of the vowels," J. Acoust. Soc. Am. 24, 175-184.

Prather, E., Hedrick, D., and Kern, C. (1975). "Articulation development in children aged two to four years," J. Speech Hear. Disord. 40, 179-191.

Savariaux, C., Perrier, P., and Orliaguet, J. P. (1995). "Compensation strategies for the perturbation of the rounded vowel [u] using a lip tube: A study of the control space in speech production,' J. Acoust. Soc. Am. 98, $2428-2442$.

Smith, A. (1992). "The control of orofacial movements in speech," Crit. Rev. Oral Biol. Med. 3, 233-267.

Stevens, K. N. (1972). "The quantal nature of speech: Evidence from articulatory-acoustic data," in Human Communication: A Unified View, edited by E. E. David and P. B. Denes (McGraw-Hill, New York), pp. $51-66$.

Stoel-Gammon, C., and Dunn, C. (1985). "Normal phonological development," in Normal and Disordered Phonology in Children, edited by C. Stoel-Gammon and C. Dunn (University Park, Baltimore), pp. 15-46.

Tanaka, H. (1973). "Speech patterns of edentulous patients and morphology of the palate in relation to phonetics," J. Prosthet. Dent. 29, 16-28.

Waldstein, R. S., and Baum, S. R. (1991). "Anticipatory coarticulation in the speech of profoundly hearing-impaired and normally hearing children,' J. Speech Hear. Res. 34, 1276-1285.

Winitz, H., Scheib, M., and Reeds, J. (1972). "Identification of stops and vowels for the burst portion of $/ \mathrm{p}, \mathrm{t}, \mathrm{k} /$ isolated from conversational speech,", J. Acoust. Soc. Am. 51, 1309-1317. 